\title{
Relationship between Total circumference (TC), Body Height, Weight and Body Mass Index (BMI) with Blood Pressure (BP): A probable cause of Hypertension within male students of Rajshahi University.
}

\author{
M.E.H.Sharker ${ }^{1}$, M.A.Islam ${ }^{1}$, M. K. Zaman ${ }^{2}$, K.M.F.Haque ${ }^{2}$ \\ and M.A.A. Mamun \\ 1 (Microbiology Lab, Department of Genetic Engineering and Biotechnology, University of Rajshahi, Rajshahi \\ 6205, Bangladesh) \\ ${ }^{2}$ (Protein Science Lab, Department of Genetic Engineering and Biotechnology, University of Rajshahi, Rajshahi \\ 6205, Bangladesh).
}

\begin{abstract}
The present study was aim to evaluate the relationship between TC and BMI with BP of 500 male students of the University of Rajshahi, Bangladesh, ageing from 18 to 27 years, having different family size and income. The samples were classified into three groups which are age, family size and income. The samples were issued randomly and calculated mean, standard deviation and coefficient correlation. It was found that mean value systolic and diastolic (BP), TC, height, weight and BMI is positively correlated with increasing age and family income whereas decreased values were found in family sizes but BMI remain unchanged in all groups. Age is strongly correlated with systolic BP $(r=0.668, p<0.05)$ while TC is significantly correlated with systolic blood pressure in age group $(r=656, p<0.05)$ but height, weight and BMI are not significantly correlated with blood pressure in age group. Weight and BMI are significantly correlated with both of systolic and diastolic BP in family income groups ( $r=0.795$ and $0.780, p<0.01$ and $r=0.780$ and $0.781, p<0.01$ ) whereas TC is significantly correlated with only systolic blood pressure $(r=0.805, p<0.01)$ in this groups. TC and BMI are also positively and significantly correlated with diastolic $B P(r=0.644,0.729, p<0.05,0.01)$ in family size group however. This study assumed that total circumference (TC) may be used for the prediction of hypertension along with height-weight and BMI in young male aged between 18 - 27 years belonging to different socio-economic group.
\end{abstract}

Keywords: Blood Pressure, Body Mass Index Hypertension \& Total circumference.

\section{Introduction}

Blood pressure is a product of peripheral vascular resistance and cardiac output. When hypertension is the result of another disease process, it is referred to as secondary hypertension. When no identifiable cause can be found, it is referred to as primary or essential hypertension. Hypertension is one of the vital risk factors for stroke and coronary heart disease in adults [1]. Ahrens (1979) reported that high blood pressure is the third most important diet related disease, which is responsible for more than $50 \%$ of deaths in developed countries [2]. Moreover, the results of the earlier work suggested that hypertension occurs ten times more frequently in persons $20 \%$ or more above their ideal body weight and reduction in body weight decreases blood pressure in obese persons [3], [4]. The prevalence of hypertension and diabetes mellitus is more than twice common in obese than it is in normally built individuals. Cardiovascular complications like hypertension and cardiovascular disease mortality rate is more than between two and four time higher in obese than normal built individuals [5]. The prevalence of overweight and obesity is estimated to be a major leading cause of mortality and morbidity, causing an estimated 2.6 million deaths worldwide and $2.3 \%$ of the global burden of disease [6]. Obesity is also defined as a BMI which associated with increased incidence of cardiovascular disease, diabetes mellitus, certain types of cancer and hypertension [7], [8]. This fat deposition in obese person may be generalized or may occur preferentially in different adipose tissue compartments [9]. It has been reported that in adults the blood pressure is related inversely to aerobic fitness and directly to fatness especially to fat deposited centrally rather than peripherally [10]. The issue of overweight and obesity has become a serious public health concern throughout the world during the last few decades. The association between overweight and hypertension depends on the variability of the prevalence of overweight in a given population [11] and age, sex, and ethnicity are potential cofounders [12]. Many factors including heredity, diet, stress, and obesity, may play a role in the development of essential hypertension [13]. The use of different type of indices poses problems for investigators seeking to determine the average differences in blood pressure associated with given differences in weight. One of the problems with common weight-height tables and indices is their failure to discriminate between muscle and fat 
weight in individuals and is based on ideal proportion of weight to height [14]. When people exceed certain cutoff points, they are assumed to be fat. But this assumption is not true for lean individuals who are especially muscular and therefore, weigh more than average people of equivalent height (e.g. players, labours). Conversely, weight-height indices may not identify some individuals who fall within acceptable weight ranges but truly have excess body fat relative to their lean mass and has been suggested that circumference methods better estimate the percentage of body weight attributable to fat with weight-height measures [14]. Estimates of percentage body fat are made with equations based on circumference measures typically involving area prone to excess fat accumulation, such as the neck, upper arm and waist circumferences called total circumferences (TC) . Waist circumference (WC) is uniformly distributed of adipose tissue among several fat compartments in the [14] abdominal region which strongly linked to obesity-associated risks [1], [15]. Social class differences in height and weight of children are well known from many studies in a wide variety of diverse societies. It has been shown that children in least developed countries, socialist countries and capitalist countries vary in the extent of social class differences, but in all studies, the higher the social class, the larger the children [16]. Considering all the view of points, the present studies was carried out to determine the association of total circumferences (upper arm, neck and waist), body height, weight and Body Mass Index (BMI) with blood pressure in age, family size and income which helps us to understand the patterns of high BP in young populations as well as in populations where the prevalence of obesity is growing. Such information would thus be relevant to the prevention and control of hypertension in our country.

\section{Materials and methods}

The samples used in that study were collected randomly from different locations (Hosain Shaheed Sohrawardi Hall, Bangbandhu Sheikh Mujibur Rahman Hall, Shere-e Bangla A.K Fazlul Haque Hall and Shaheed Ziaur Rahman Hall) in University of Rajshahi. A sample of 500 male students ageing from $18-27$ years, having different family size $(2-12)$ and income $(8000-50000)$ were used for this experiment. The blood pressure $(\mathrm{mm} \mathrm{Hg})$ was measured using sphygmomanometer (Hawk sly random zero) and stethoscope (Littmann) with standard blood pressure cuff as described by Khan et al. (2001) [17]. The first korotkoff sound was considered to be the systolic blood pressure (SBP) value and the fourth as diastolic blood pressure (DBP) value. Neck, upper arm, waist circumferences and height were measured in the unit of centimeter with the help of measuring tape followed the method of Chan et al. (2003) [15]. The upper arm was measured at the point where it has maximum circumference and waist circumferences was measured at the spot of umbilical chord whereas neck circumference was taken just below the larynx. The sum of all these circumferences (upper arm, waist and neck) was considered as total circumference (TC). The weight was measured with weight machines. Body mass index (BMI) is calculated by the following equation.

BMI=Weight $(\mathrm{kg}) /$ Height $^{2}(\mathrm{~m})$.

Age, family size and income were collected directly as information from students whose were used as sample materials in our investigation. The samples are classified into three independent (age, family size and income) and ten dependent (systolic and diastolic BP, neck, upper arm and waist circumferences, TC, height, weight and BMI) variables. All the collected data of age are classified into 10 groups (age of 18, 19, 20, 21, 22, $23,24,25,26$ and 27) whereas family size are classified into 11 groups (family size of $2,3,4,5,6,7,8,9,10$, 11 and 12) and family income are classified into 9 groups (family income of 8000, 1000, 12000, 15000, 20000, $25000,30000,35000$ and 50000) which expressed generally as mean \pm SEM. The basic statistical constants and association indices (coefficient of correlation) were calculated within the dependent and independent variable using Microsoft Office Excel 2007.

\section{Results}

The results of the mean value of all dependent variables in age, family size and family income groups are shown in figure 1, 2, 3, 4, 5 and 6 . The figure shows that blood pressure (BP) is increased with the increasing of age and family income (fig 1 and 5) whereas BP is decreased with the increasing of family size (fig 3). TC, height and weight are also increased with the increasing of age and family income (fig 1,2,5 and 6) but decreased value was found with the increase of family size (fig 3 and 4). BMI is not significantly changed with the increase of age, family size and family income (fig 2, 4 and 6).

The results of the coefficient of correlation between age, family size and family income with all dependent variables are shown in table 1,2 and 3. The tables' represents that all dependent variables are positively correlated with age and family income (table 1 and 3 ) but negatively correlated with family size (table 2). Age is significantly correlated with systolic $\mathrm{BP}(\mathrm{r}=0.668, \mathrm{p}<0.05)$, TC $(\mathrm{r}=907, \mathrm{p}<0.001)$, height $(\mathrm{r}=0.992$, $\mathrm{p}<0.001)$, weight $(\mathrm{r}=0.904, \mathrm{p}<0.001)$ and BMI $(\mathrm{r}=0.922, \mathrm{p}<0.001)$ whereas only TC is significantly correlated with systolic blood pressure in age group $(\mathrm{r}=656, \mathrm{p}<0.05)$ (Table 1). Height, weight and BMI are not significantly correlated with blood pressure between age groups (Table1). Family income is significantly correlated with TC $(r=0.930, p<0.001)$, weight $(r=0.932, p<0.001)$ and BMI $(r=0.902, p<0.001)$ whereas 
weight and BMI are significantly correlated with both of systolic and diastolic BP in Family income groups ( $\mathrm{r}=$ 0.795 and $0.780, p<0.01$ and $r=0.780$ and $0.781, p<0.01$ ) (Table 3 ) but $\mathrm{TC}$ is significantly correlated with only systolic blood pressure $(\mathrm{r}=0.805, \mathrm{p}<0.01)$ in this groups. Family size is negatively correlated with all the dependent variables but TC and BMI are positively and significantly correlated with diastolic BP $(\mathrm{r}=0.644$, $0.729, \mathrm{p}<0.05,0.01$ ) in this group (Table 2).

Figure1. Results of the Mean of SBP, DBP and Total circumference in case of Age.

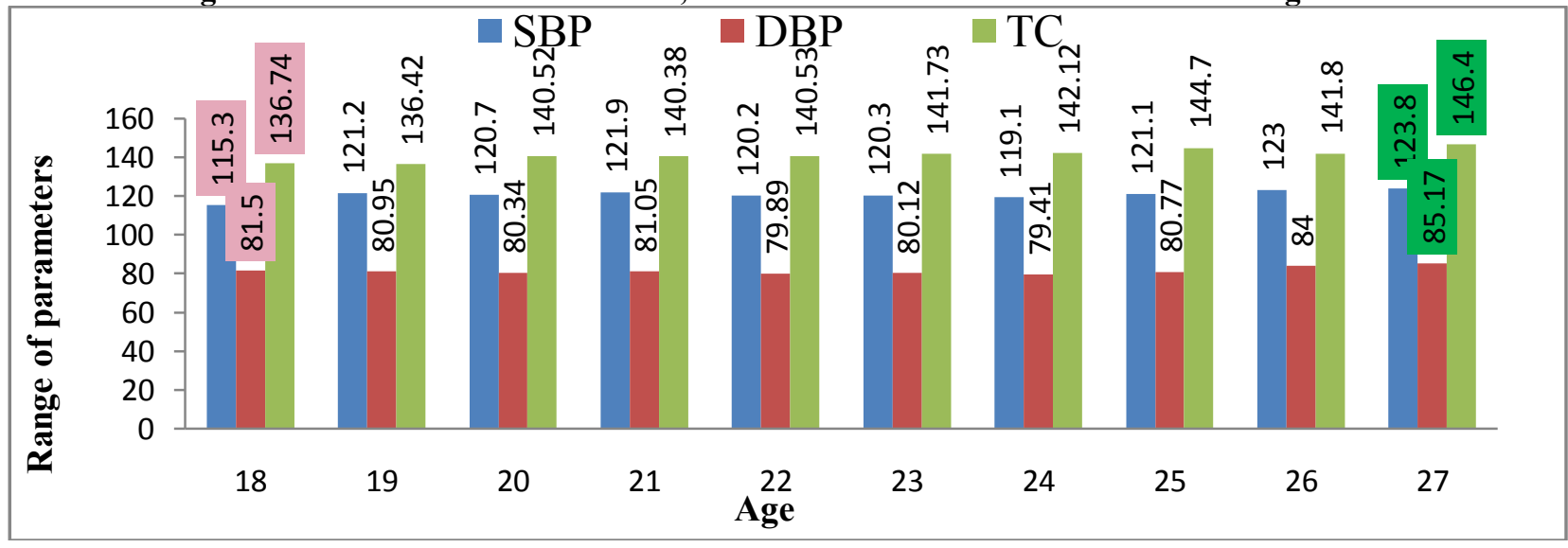

Figure2. Results of the Mean of Body height, weight and BMI in case of Age.

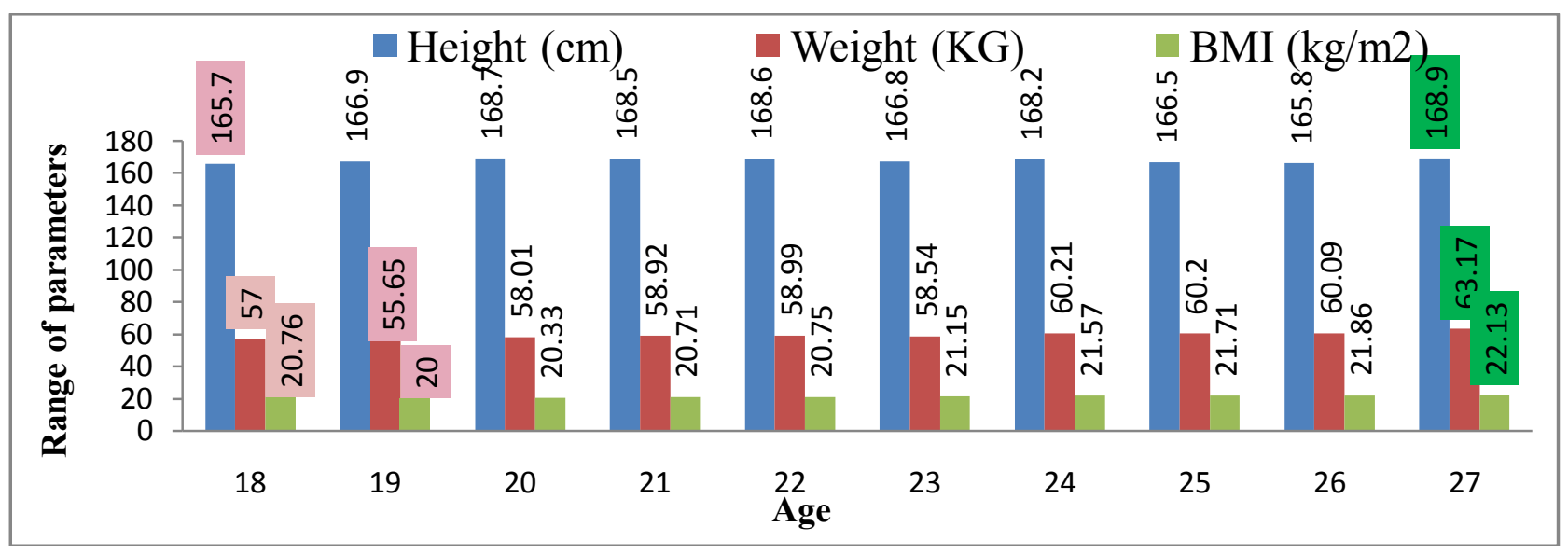

Figure 3. Results of the Mean of SBP, DBP and total circumference in case of Family size.

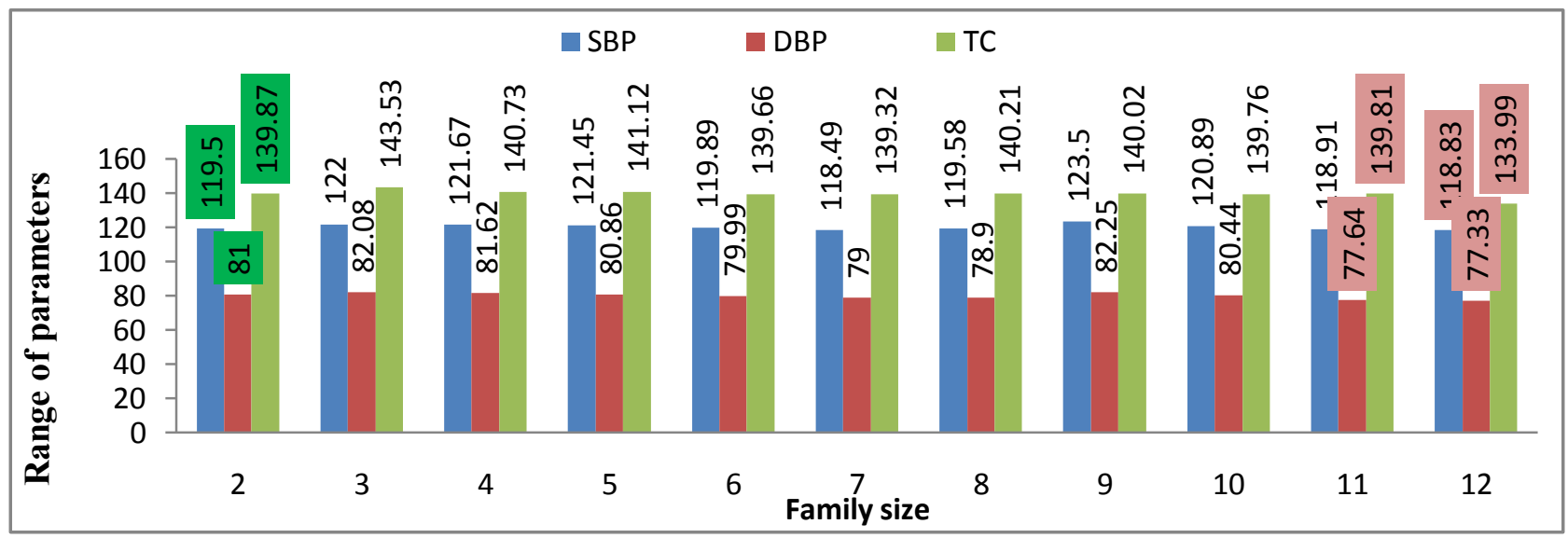

Note: Green and pink color indicate the highest and lowest mean value uniformly.

Figure 4. Results of the Mean of Body height, weight and BMI in case of Family size. 


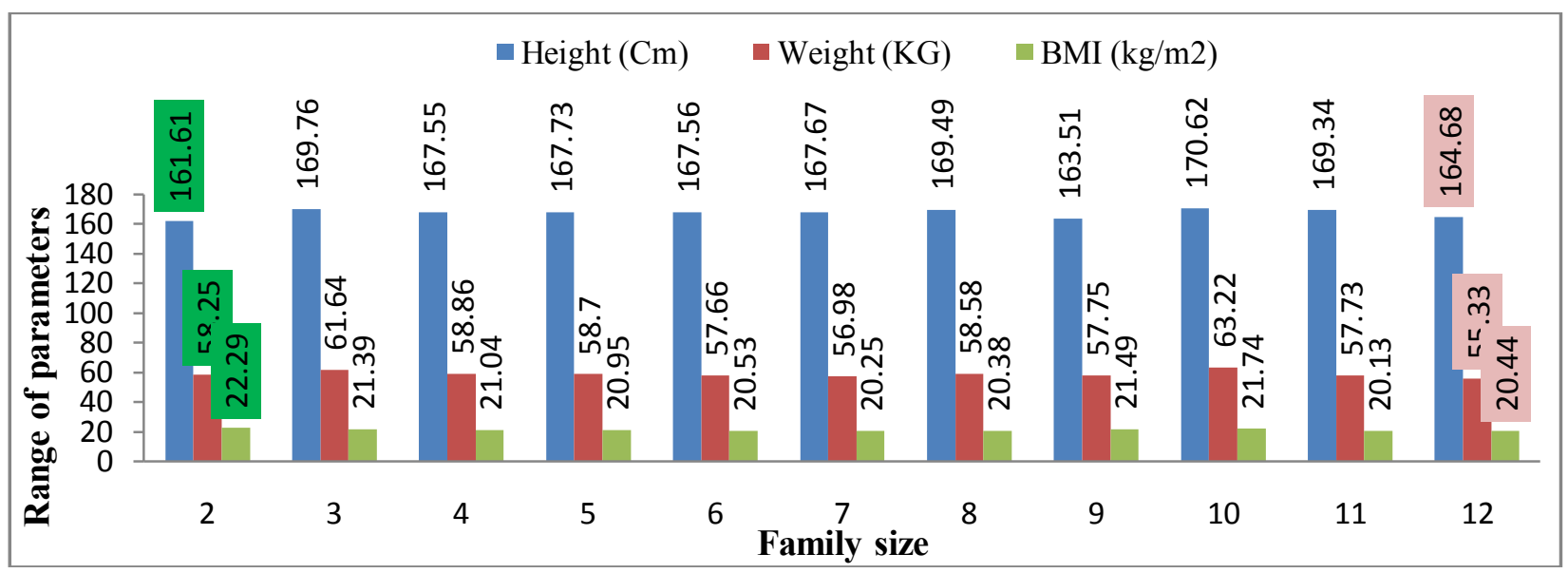

Figure 5. Results of the Mean of SBP, DBP and total circumference in case of Family income.

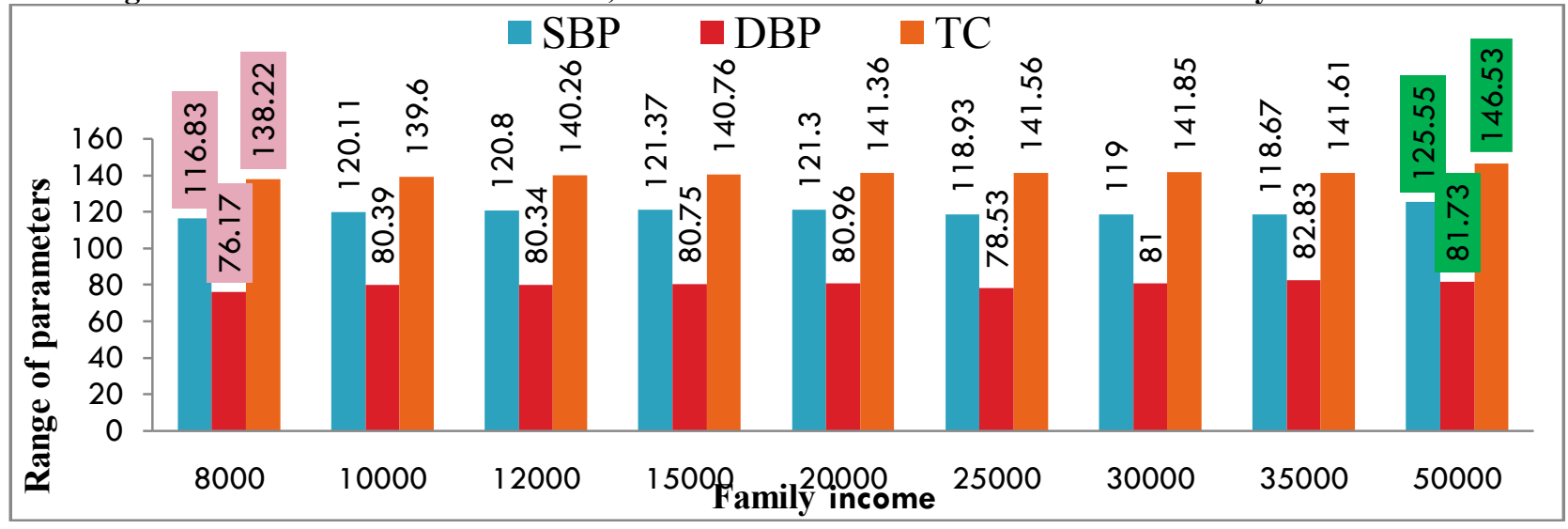

Figure 6. Results of the Mean of Body height, weight and BMI in case of Family income.

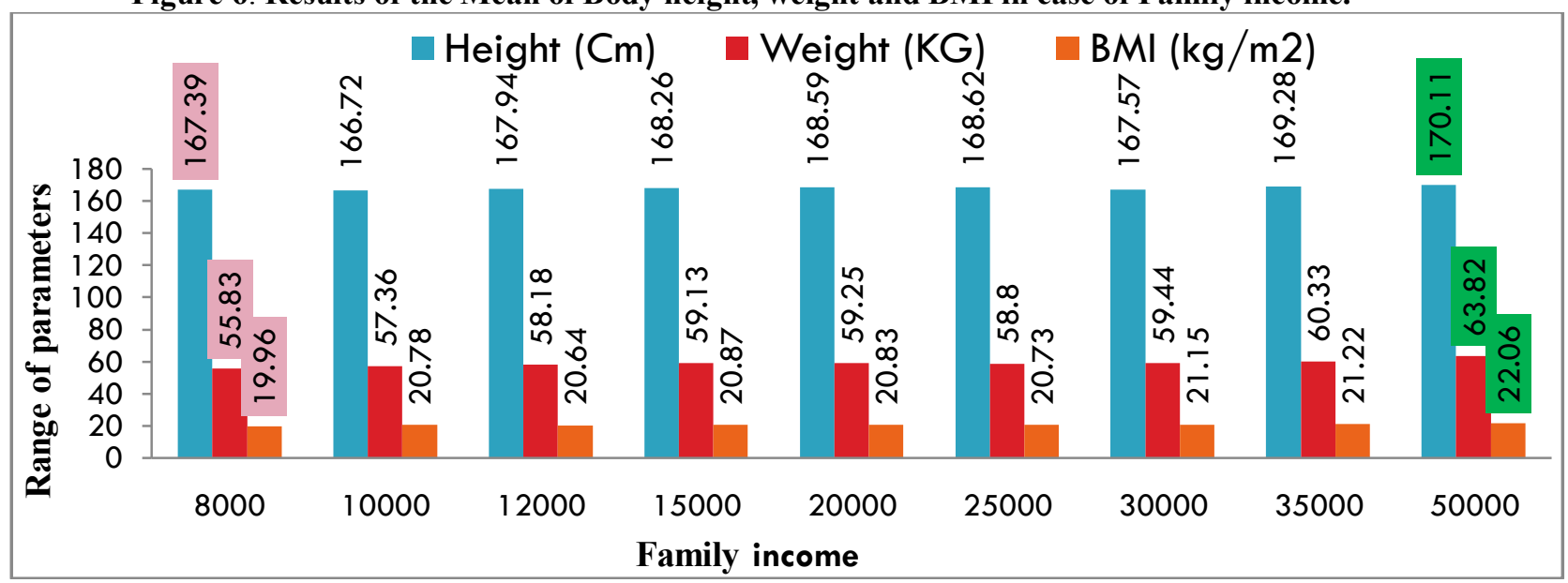

Note: Green and pink color indicate the highest and lowest mean value uniformly. 
Table 1. Results of the Coefficient of Correlation between Age.

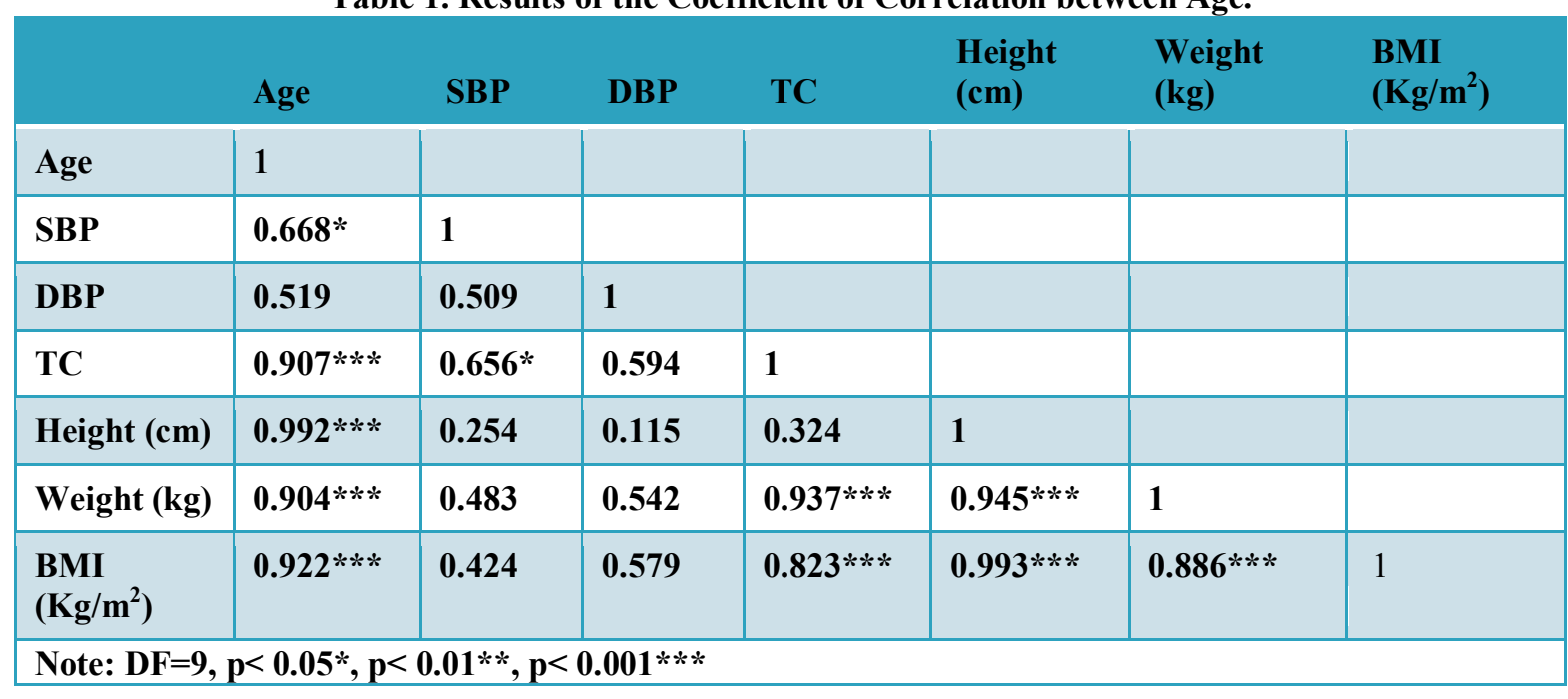

Table 2. Results of the Coefficient of Correlation between Family Size

\begin{tabular}{|c|c|c|c|c|c|c|c|}
\hline & Family size & SBP & DBP & TC & $\begin{array}{l}\text { Height } \\
\text { (cm) }\end{array}$ & $\begin{array}{l}\text { Weight } \\
\text { (cm) }\end{array}$ & $\begin{array}{l}\text { BMI } \\
\left(\mathrm{Kg} / \mathrm{m}^{2}\right)\end{array}$ \\
\hline Family size & 1 & & & & & & \\
\hline SBP & -0.285 & 1 & & & & & \\
\hline DBP & -0.686 & $0.850 * * *$ & 1 & & & & \\
\hline TC & -0.436 & 0.524 & $0.644 *$ & 1 & & & \\
\hline Height (cm) & -0.175 & -0.041 & -0.154 & 0.530 & 1 & & \\
\hline Weight (cm) & -0.254 & 0.446 & 0.521 & 0.535 & 0.559 & 1 & \\
\hline $\begin{array}{l}\text { BMI } \\
\left(\mathrm{Kg} / \mathrm{m}^{2}\right)\end{array}$ & -0.488 & 0.518 & $0.729 * *$ & 0.459 & -0.399 & $0.905 * * *$ & 1 \\
\hline
\end{tabular}

Table 3. Results of the Coefficient of Correlation between Family Income.

\begin{tabular}{|c|c|c|c|c|c|c|c|}
\hline & $\begin{array}{l}\text { Family } \\
\text { income }\end{array}$ & SBP & DBP & $\mathbf{T C}$ & $\begin{array}{l}\text { Height } \\
\text { (cm) }\end{array}$ & $\begin{array}{l}\text { Weight } \\
\text { (cm) }\end{array}$ & $\begin{array}{l}\text { BMI } \\
\left(\mathrm{Kg} / \mathrm{m}^{2}\right)\end{array}$ \\
\hline $\begin{array}{l}\text { Family } \\
\text { income }\end{array}$ & 1 & & & & & & \\
\hline SBP & 0.547 & 1 & & & & & \\
\hline DBP & 0.589 & 0.544 & 1 & & & & \\
\hline TC & $0.930 * * *$ & $0.805 * *$ & 0.583 & 1 & & & \\
\hline $\begin{array}{l}\text { Height } \\
\text { (cm) }\end{array}$ & 0.538 & 0.596 & 0.646 & $0.821 * * *$ & 1 & & \\
\hline $\begin{array}{l}\text { Weight } \\
\text { (cm) }\end{array}$ & $0.932 * * *$ & $0.795 * *$ & $0.708 * *$ & $0.978 * * *$ & $0.861 * * *$ & 1 & \\
\hline $\begin{array}{l}\text { BMI } \\
\left(\mathrm{Kg} / \mathrm{m}^{2}\right)\end{array}$ & $0.902 * * *$ & $0.780 * *$ & $0.781 * *$ & $0.944 * * *$ & $0.718 * *$ & $0.967 * * *$ & 1 \\
\hline
\end{tabular}




\section{Discussion:}

The present study recorded the association of total circumference (neck, upper arm, and waist), body weight and height, body mass index with systolic and diastolic blood pressures. The main findings of our study were that the mean of systolic and diastolic BP, total circumference (TC), height and weight increased gradually with the increasing of age and family income but decreased gradually with the increasing of family size whereas BMI is not significantly changed with the increase of age, family size and family income. This result is accords with the findings reported by Tesfaye F et al (2007) [18] in Ethiopia and Indonesia. In the present study, systolic and diastolic BP are positively and systolic BP is significantly correlated with age $(\mathrm{r}=0.668, \mathrm{p}<0.05)$ while total circumference is also associated with systolic BP $(r=656, p<0.05)$. A similar pattern has been reported in other studies [19]. A significant correlation between SBP and age was also reported in another study from India [20]. The study demonstrated that family income is positively correlated with both systolic and diastolic BP while BMI is strongly associated with both of systolic and diastolic BP ( $r=0.780$ and $0.781, p<0.01)$ and TC is only associated with systolic BP $(\mathrm{r}=0.805, \mathrm{p}<0.01)$. This observation suggests that higher social class individuals develop characteristic increase in body mass index (BMI) and total circumference (neck, upper arm, and waist) which may be an important risk factor for hypertension. A significantly higher mean SBP and DBP among urban than rural men was reported in elderly populations of North India [20]. The association between BMI and BP has been widely reported across populations in Asia, Latin America, United States and Canada. Early increase in weight and body mass index in hypertensive individuals has been reported by multiple researchers [21]. A recent study in white Canadian population presented data on the effect of overweight and systolic and diastolic blood pressure, a strong association of body mass index with hypertension was found [22]. As an additional comment, the prevalence of increased weight and body mass index may be related to the increased blood pressure in Mexico in the last generations [23]. Among the very few studies available from the African continent on the BMI and BP relationship, there was a report that BMI is positively associated with BP in the urban population of Dar es Salaam, Tanzania [24]. In our study a negative correlation was found between family income with BMI, TC and both of Systolic and diastolic BP, however TC and BMI are positively and significantly correlated with diastolic BP $(r=0.644,0.729, \mathrm{p}<0.05,0.01)$ in this group. We hypothesize that declining lack of access to health and other social services are commonly encountered by adult's people in larger family settings. In such populations, the cumulative exposure to poverty, diseases and nutritional deprivation throughout childhood, adolescence and adulthood might contribute to progressive decline of the BMI and TC. This is evidenced by the high prevalence of under-nutrition (low BMI and TC) among young population in Rajshahi region of Bangladesh. Finally from our study we strongly depicted that TC and BMI are not individually but combined leading the hypertension in different age and socio- economic group.

\section{Conclusion}

The current study obviously demonstrated that the mean of systolic and diastolic BP, total circumference (TC), height and weight increased gradually with the increasing of age and family income but decreased gradually with the increasing of family size whereas BMI is not significantly changed with the increase of age, family size and family income. This result may be due to take up rich food stuff by higher class family resulting stoking mass adipose tissue in their body and subjected hypertension. The living materials are distributed among the family member of larger family size and their member may starvation for food. This situation may be occurred in the low income family. So our present observation suggested that all class of people especially higher class should take balanced diet and family size should have minimum standard to remedy for hypertension.

\section{Acknowledgement}

I would like to acknowledge ministry of science and technology of Bangladesh for financial support.

\section{Reference}

[1] Zhu SK, Wang ZM, Heshka S, Heo M., Faith MS. and Heymsfield SB. Waist circumference and obesity-associated risk factors among whites in the third National Health and Nutrition Examination Survey: clinical action thresholds. Amer. J. Clin. Nut, 2002, 76(4): 743.

[2] Ahrens EH. The evidence relating six dietary factors to the Nation's health. Amer. J. Clin. Nut, 1979, 32(12), $2627-2631$.

[3] Harlan WR, Hull AL. and Schmodder RL. Blood pressure and nutrition in adults. The National Health and Nutrition Examination Survey Amer. J. Epidemiol, 1984, 120(1), 17-28.

[4] Treuth MS, Butte NF and Wong WW. Effects of familial predisposition to obesity on energy expenditure in multiethnic prepubertal girls. Amer. J. Clin. Nut, 2000, 71(4): 893-900

[5] Moore VM, Cockington RA, Ryan P and Robinson JS. The relationship between birth weight and blood pressure amplifies from childhood to adulthood. J. Hyperten, 1999, 17: 883-888. 
[6] Ezzati M, Martin H, Skjod S and Hoorn SV. Trends in National and State-Level Obesity in the USA after correction for self-report bias: Analysis of Health Surveys. J. R. Soci. Med, 2006, 99:250-257.

[7] Kanne WB, Zhang T and Garrison RJ. Is obesity-related hypertension less of a cardiovascular risk? Am. Heart J, 1990, 120: 11951201.

[8] Goodman E and Whitaker RC. A prospective study of the role of depression in the development and persistence of adolescent obesity. Pediatrics, 2002, 111(3): 497-504.

[9] Grundy SM. and Abate N. 2003. Obesity. Chapter 2, Secondary Heart Disease (Systemic Diseases and the Heart) 2003, CAR-S8 02(1463-1468). Available

[10] Blair D, Habict J and Sims PE. Evidence for an increased risk for hypertension with centrally located body fat and the effect of race and sex on this risk Amer. J. Epidemiol, 1984,119 (4), 526-540.

[11] Dyer AR, Elliot P and Shipley M. Body mass index versus height and weight in relation to blood pressure. Am. J. Epidemiol, 1990, 131: 589-596.

[12] Lackland DT, Orchard TJ, Keil JE, Saunders DE, Wheeler FC, Adams-Campbell LL, McDonald RH and Knapp RG. Are race differences in the prevalence of hypertension explained by body mass and fat distribution? A survey in a biracial population. J. Epidemiol, 1992, 21: 236-245.

[13] Behrman RE, Kliegman RM and Jenson HB. Systemic hypertension. Nelson textbook of Pediatrics, 17th ed. Philadelphia, Saunders, 2004, 437: 1592-1598.

[14] Hodgdon JA.and Backett MB. Naval Health Research Centre, San Diego, CA, 1984

[15] Chan DC, Watts GF, Barrett PHR and Burke V. Waist circumference, waist-to-hip ratio and body mass index as predictors of adipose tissue compartments in men. Q. J. Med, 2003, 96: 441-447.

[16] Johnston FE. 1986 "Human Growth" F. Falkner and J.M. Tanner (Eds.) Plenum Press, New York.

[17] Khan TH, Mahmud Z M, Farooq A and Manzoor U. The effects of family size on the relationship of blood pressure with circumferences in the female students of Bahauddin Zakariya University, Multan, Pakistan. J. Res. (Sc.). Bahauddin Univ, 2001, 12(2): 207-213.

[18] Tesfaye F, Nawi NG , Van Minh H, Byass P ,Berhane Y, Bonita R and Wall S. Association between body mass index and blood pressure across three populations in Africa and Asia. Journal of Human Hypertension, 2007, 21: 28-37

[19] Mufunda J, Mebrahtu G, Usman A, Nyarango P, Kosia A and Ghebrat Y. The prevalence of hypertension and its relationship with obesity: results from a national blood pressure survey in Eritrea. J. Hum. Hypertens, 2006, 20: 59-65.

[20] Singh RB, Rastogi SS, Rastogi V, Niaz MA, Madhu SV and Chen M. Blood pressure trends, plasma insulin levels and risk factors in rural and urban elderly populations of north India. Coron. Artery Dis, 1997, 8: 463-468.

[21] Arroyo P, Fernandez V and Hector AR. Overweight and hypertension. Hypertension, 1997, 30: 646.

[22] Chen Y, Rennie DC and Reeder BA. Age-related association between body mass index and blood pressure. The Humbolt study. Int. J. Obes, 1995, 19: 825-83

[23] Velazquez MT. Dinamica poblacional Y medio ambiente. Ciencias, 1996, 44: 56-63

[24] Bovet P, Ross AG, Gervasoni JP, Mkamba M, Mtasiwa DM. and Lengeler C. Distribution of blood pressure, body mass index and smoking habits in the urban population of Dar es Salaam, Tanzania, and associations with socioeconomic status. Int. J. Epidemiol, 2002, 31: 240-247. 